\title{
CORROSION RESISTANCE OF X5CrNi18-10 STAINLESS STEEL
}

\begin{abstract}
The paper presents the influence of heat treatment on the structure and corrosion resistance of X5CrNi18-10 steel. To determine the structure which has been obtained after heat treatment the methods of light and scanning electron microscopy with EDS microanalysis were used. The electrochemical corrosion properties of the investigated steel were studied in $3.5 \% \mathrm{NaCl}$ solution using potentiodynamic polarization tests. Basing on the registered curves, the corrosion current, polarization resistance and corrosion potential were determined. The corrosion tests were followed by fractographic researches.

Keywords: austenitic stainless steel, sensitization, corrosion resistance, potentiodynamic tests.
\end{abstract}

\section{Introduction}

Austenitic steels are non-magnetic materials that contain high levels of chromium and nickel, and low levels of carbon. While ferritic steels have a body-centered cubic (BCC) grain structure, the austenitic stainless steels are characterized by their face-centered cubic (FCC) crystal structure. This grain structure forms when a sufficient quantity of nickel is added to the alloy $(8-10 \%)$, but $8 \%$ is the minimum amount of nickel that can be added to a stainless steel containing $18 \%$ chromium in order to completely convert all the ferrite to austenite. For the same purpose the austenite former manganese is added to the steel. Due to the fact that the solubility of carbon in austenite at ambient temperature does not exceed $0.04 \%$, the excess is bounded in the precipitated chromium carbides and therefore carbide forming elements such as $\mathrm{Ti}$ and $\mathrm{Nb}$ are introduced to steel. Molybdenum $(1.5-3 \%)$ is essential in order to improve corrosion resistance to sulphuric acid [1-3].

Austenitic stainless steels are characterized by excellent mechanical properties, weldability and corrosion resistance in most corrosive environments. These steels have good corrosion resistance because of the presence of chromium and formation of a self-healing protective film of chromium oxide [4-8]. The film is stable, invisible, very thin, durable, extremely adherent and self-repairing [9]. These steels also have very good strength at extremely low temperatures so are used extensively in cryogenic applications. They can be hardened and their strength can be increased by cold working.

The steels found application in many industries and in medical applications for example: chemical, petrochemical, machinery, automotive and shipbuilding industries.
If these alloys were to have any relative weaknesses, they would be [2]:

- because thermal expansion coefficient of austenitic stainless steels tends to cause the protective oxide coating to spall so they are less resistant to cyclic oxidation than ferritic grades.

- they are susceptible to stress corrosion cracking.

- the fatigue endurance limit is about $30 \%$ of the tensile strength (vs. about $60 \%$ for ferritic stainless steels). This makes them susceptible to thermal fatigue, additionally taking into account their high coefficients of thermal expansion.

Problems of stability of the materials in natural and artificial environments are extremely important in the design and use of the constructions and devices. Corrosive destruction is one of the major sources of materials loss. It contributes simultaneously to environmental pollution and poses a threat to human health.

In the case of austenitic stainless steels, the destruction of the material due to intergranular corrosion is related to the chromium carbides precipitates at the grain boundaries, which causes the depletion of the chromium in border areas of austenite grains, to below $12 \%$ (Fig. 1) [10]. This zones with low concentration of chromium have also very unstable austenite and is quite prone to martensite formation. The strain-induced martensite along the grain boundaries caused intergranular fracture [11].

This process is observed as a result of the solubility changes of carbon in austenite, which depends on the temperature. The solubility of carbon in austenite depends highly on temperature, and its solubility decreases greatly with reduction of temperature. In temperature $800^{\circ} \mathrm{C}$ the solubility of carbon is $0.03 \%$, remaining at a constant level, until it reaches the room temperature.

\footnotetext{
* SILESIAN UNIVERSITY OF TECHNOLOGY, INSTITUTE OF ENGINEERING MATERIALS AND BIOMATERIALS, 18A KONARSKIEGO STREET, 44-100 GLIWICE, POLAND

** SILESIAN UNIVERSITY OF TECHNOLOGY, FACULTY OF MECHANICAL ENGINEERING, 18A KONARSKIEGO STREET, 44-100 GLIWICE, POLAND

\# Corresponding author: monika.kciuk@polsl.pl
} 
After isothermal heat treatment within the temperature range from $500^{\circ} \mathrm{C}$ to $800^{\circ} \mathrm{C}$ the austenitic stainless steels became more susceptible to intergranular corrosion (sensitization) $[12,13]$. Because carbon diffuses several orders of magnitude more rapidly than chromium, carbon diffuses to and combines with chromium essentially in situ, depleting the grain boundaries of chromium in solution [2]. Grain boundaries are much less resistant to aggressive environments (anode) compared to the surrounding grains (cathode) [14].
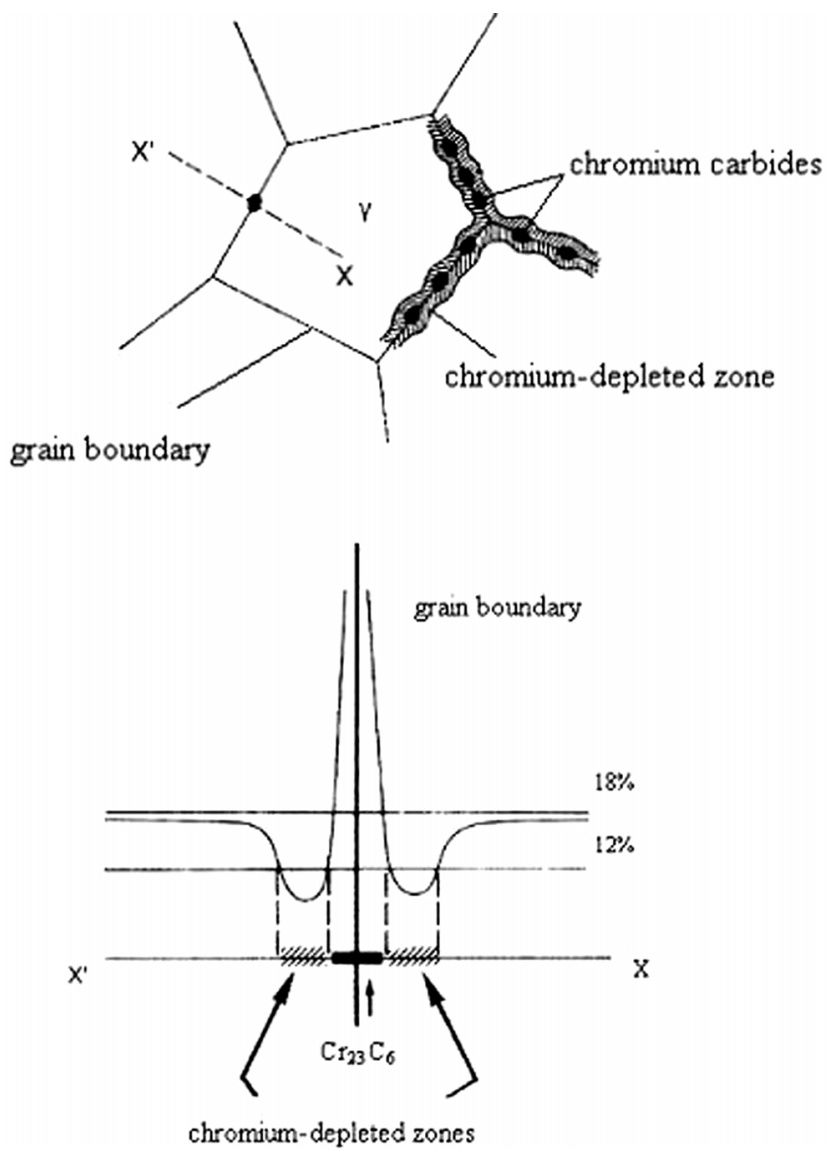

Fig. 1. Precipitation of chromium carbides at the grain boundaries [2]

\section{Material and methods}

The investigations were carried out on commercially available X5CrNi18-10 steel. The chemical composition of analyzed steel is presented in Table 1.

TABLE

Chemical composition of the investigated steel

\begin{tabular}{|c|c|c|c|c|c|c|c|}
\hline \hline \multicolumn{1}{|c|}{ Chemical composition, (\% wt) } \\
\hline $\mathbf{C}$ & $\mathbf{M n}$ & $\mathbf{S i}$ & $\mathbf{P}$ & $\mathbf{S}$ & $\mathbf{C r}$ & $\mathbf{N i}$ & $\mathbf{N}$ \\
\hline 0.07 & 2 & 0.7 & 0.045 & 0.03 & 18 & 9 & 0.1 \\
\hline
\end{tabular}

Two types of heat treatment, supersaturation and sensitized heat treatments were applied to the specimens, as shown in Table 2 . The heat treatment was carried out in electric resistance furnace Nabertherm HTCT 03/16. Cooling of the samples after heat treatment was performed in water for the solution heat treatment and in the air after sensitization.

TABLE 2

Heat treatments parameters for austenitic stainless steel

\begin{tabular}{|c|c|c|c|}
\hline $\begin{array}{c}\text { Heat treatments } \\
\text { steps }\end{array}$ & $\begin{array}{c}\text { Temperature, } \\
{\left[{ }^{\circ} \mathbf{C}\right]}\end{array}$ & $\begin{array}{c}\text { Time, } \\
{[\mathbf{m i n}]}\end{array}$ & $\begin{array}{c}\text { Cooling } \\
\text { medium }\end{array}$ \\
\hline Supersaturation & 1075 & 4 & Water \\
\hline Sensitization & 700 & 70 & Air \\
\hline
\end{tabular}

The hardness tests were performed using Vickers hardness test method (HV) by a microhardness tester Wilson Wolpert 401MVD with a force of 9.81 N (HV1).

The metallographic preparations were carried out conventionally for samples in delivery state and after heat treatment. All specimens were immersed in duracryl, then mechanically grinded with $\mathrm{SiC}$ papers with various granulation, polished with $\mathrm{Al}_{2} \mathrm{O}_{3}$ water solution and finally etched using aqua regia. The metallographic examinations were performed using Zeiss Axio Observer Z1m optical microscope with $1000 \times$ magnification. Additionally, the specimen after sensitization was analyzed by scaning electron microscope Zeiss SUPRA 25 where accelerating voltage amounted to $10 \mathrm{kV}$.

Electrochemical study of corrosion resistance was conducted in accordance with the standard PN-EN ISO 17475:2008. Corrosion resistance of the material was examined by Atlas 0531 EU ATLAS-SOLLICH unit potentiostat/galvanostat and results were generated by the AtlasCorr05 software. The base steel for corrosion examinations was cut into $10 \mathrm{~mm} \times 10 \mathrm{~mm}$ plates. Before starting the corrosion tests, the surface of the material was grinded with $\mathrm{SiC}$ paper and polished with $\mathrm{Al}_{2} \mathrm{O}_{3}$ solution in order to obtain the surface without roughness and scratches. The specimens were cleaned in ethanol and dried in air before corrosion tests in $3.5 \% \mathrm{NaCl}$ solution, which was freshly prepared prior to the testing.

$\mathrm{The} \mathrm{Ag} / \mathrm{AgCl}$ electrode was used as the reference electrode, the tested steel was the anode and stainless steel as the counter electrode for current measurements. The potential was changed in the anodic direction at the rate of $0.5 \mathrm{mVs}^{-1}$. All the electrochemical tests were performed at a constant room temperature.

Fractographic examinations after corrosion test were carried out using scanning electron microscope SUPRA 25.

\section{Results and discussion}

Results of metallographic observations are shown in Figs. 2-4. It was possible to identify the influence of the applied heat treatment, consisting of annealing and sensitization on the structure of the X5CrNi18-10 steel. Based on the observation of material in delivery it was found that the structure of $\mathrm{X} 5 \mathrm{Cr}$ Ni18-10 steel consists of austenite grains with a number of slip lines and bands after plastic deformation (Fig. 2). The austenite grains with numerous annealing twins can be observed in the structure after supersaturation (Fig. 3). 

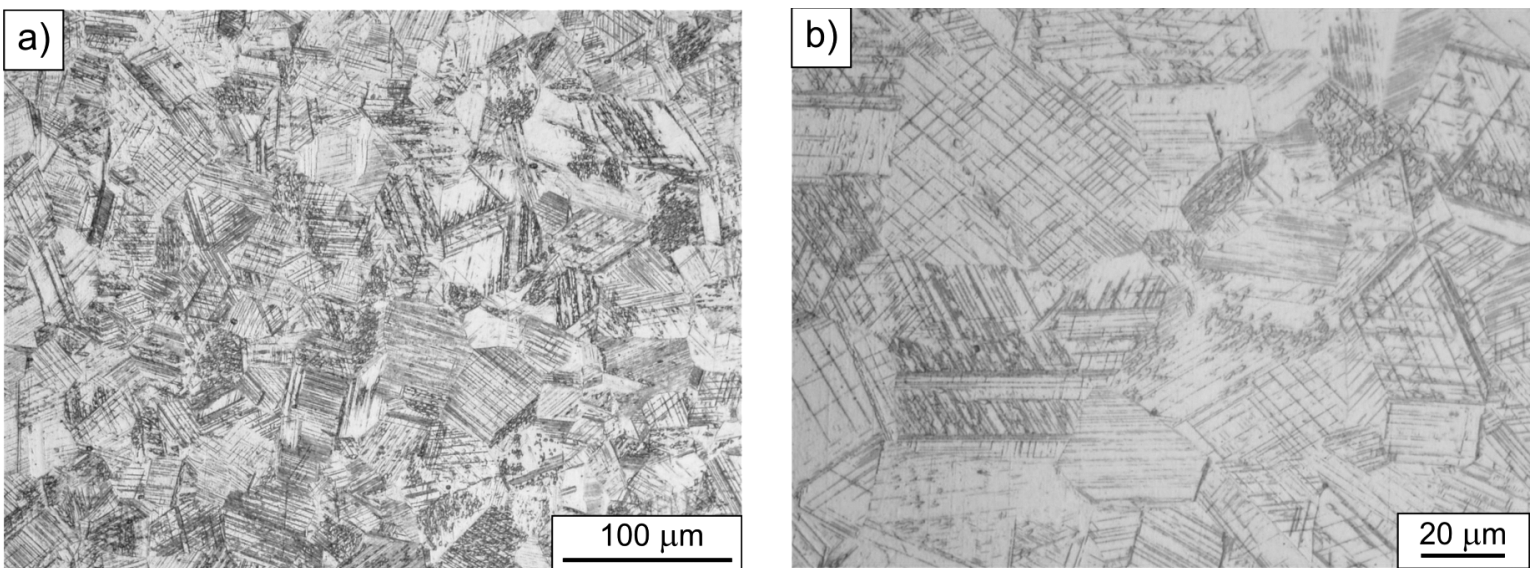

Fig. 2. Structure of X5CrNi18-10 in delivery state $500 \times$ (a), $1000 \times$ (b)
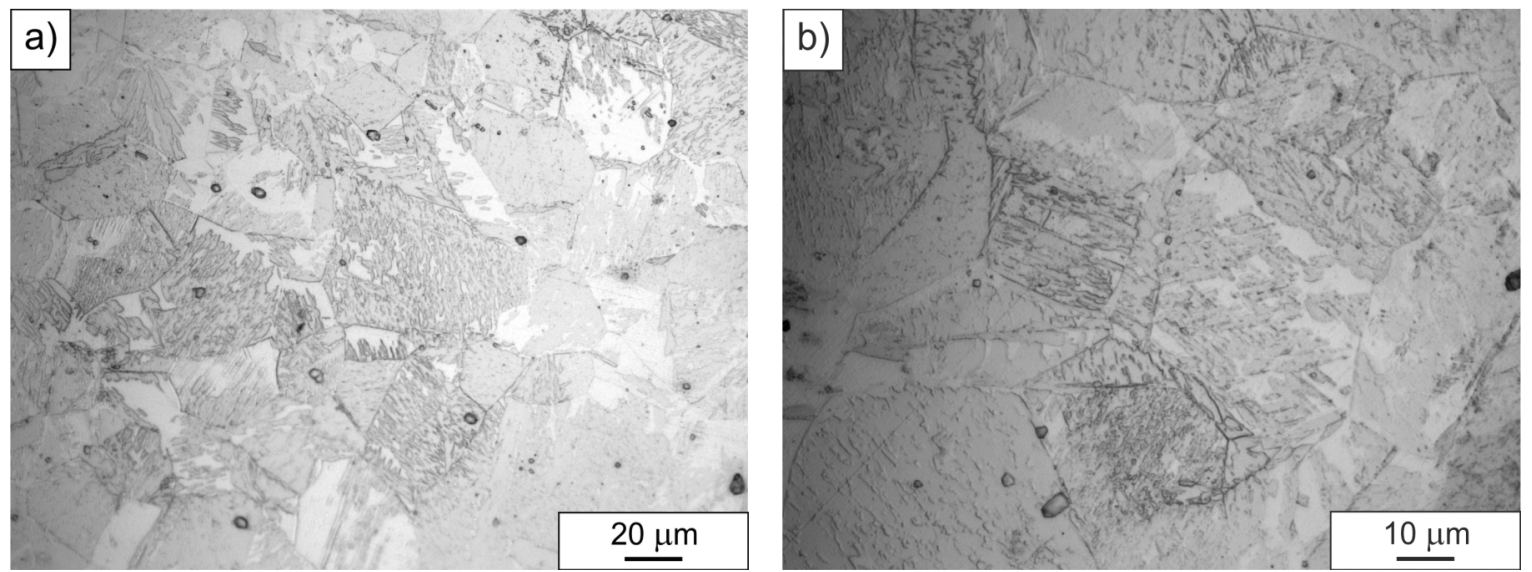

Fig. 3. Structure of $\mathrm{X} 5 \mathrm{CrNi18}-10$ after supersaturation $500 \times(\mathrm{a}), 1000 \times(\mathrm{b})$

In the structure after sensitization it was stated that $\mathrm{Cr}_{23} \mathrm{C}_{6}$ carbides are precipitated along grain boundaries (Fig. 4). With decreasing solubility of carbon in austenite precipitation of carbides is associated. Such unstable austenite is sufficiently stable at a temperature below $400^{\circ} \mathrm{C}$ and at a temperature above $500^{\circ} \mathrm{C} \mathrm{Cr}_{23} \mathrm{C}_{6}$ carbides are released from there, nucleating along grain boundaries. Because of the large difference in diffusion rate of $\mathrm{C}$ and $\mathrm{Cr}$, depletion of $\mathrm{C}$ in austenite reaches deep into the grain, and the $\mathrm{Cr}$ - only in thin layer of the border. This zone is depleted of chromium content below $13 \%$ and it causes under the influence of an aggressive environment dangerous in consequences intergranular corrosion.

Based on the conducted chemical analysis in scanning electron microscope of the precipitations along grain boundaries (Fig. 5) and inside the grain (Fig. 6) of sensitized steel the decrease concentration of chromium and carbon was revealed. It was also stated that chromium carbides tend to precipitate at the grain boundaries as continuous or intermittent carbides net.
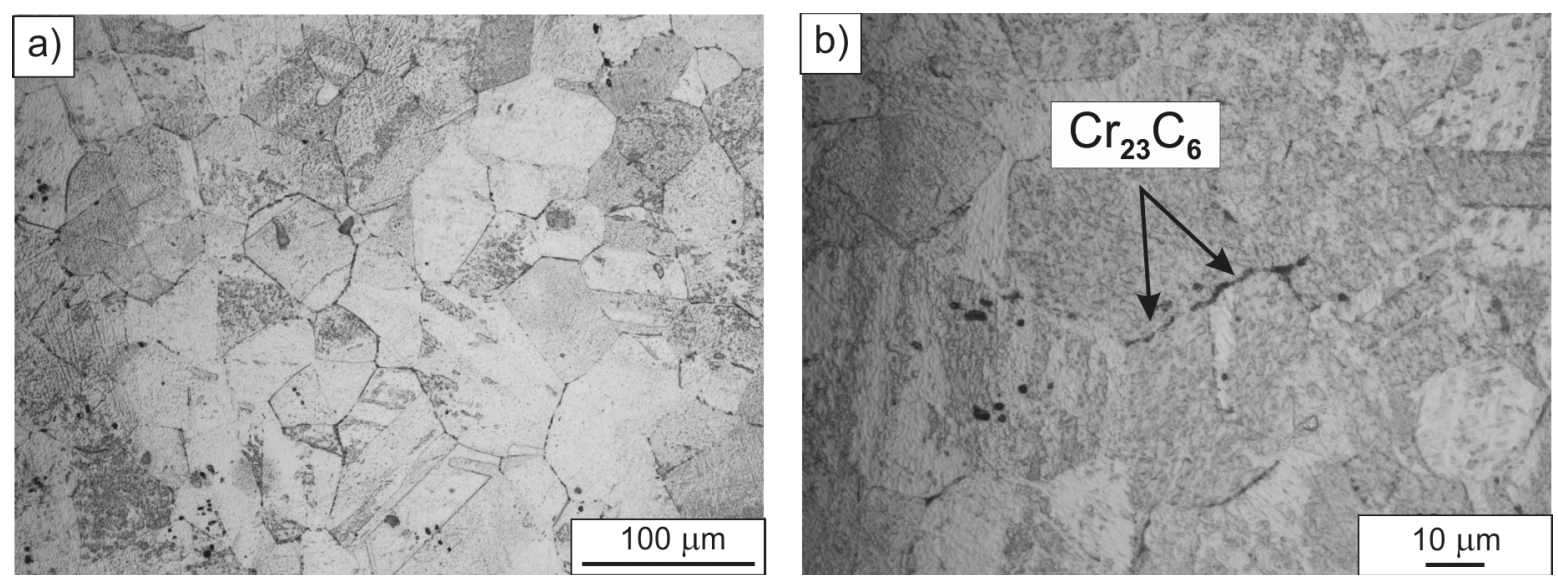

Fig. 4. Structure of $\mathrm{X} 5 \mathrm{CrNi18}-10$ after sensitization at $700^{\circ} \mathrm{C} 500 \times(\mathrm{a}), 1000 \times(\mathrm{b})$ 

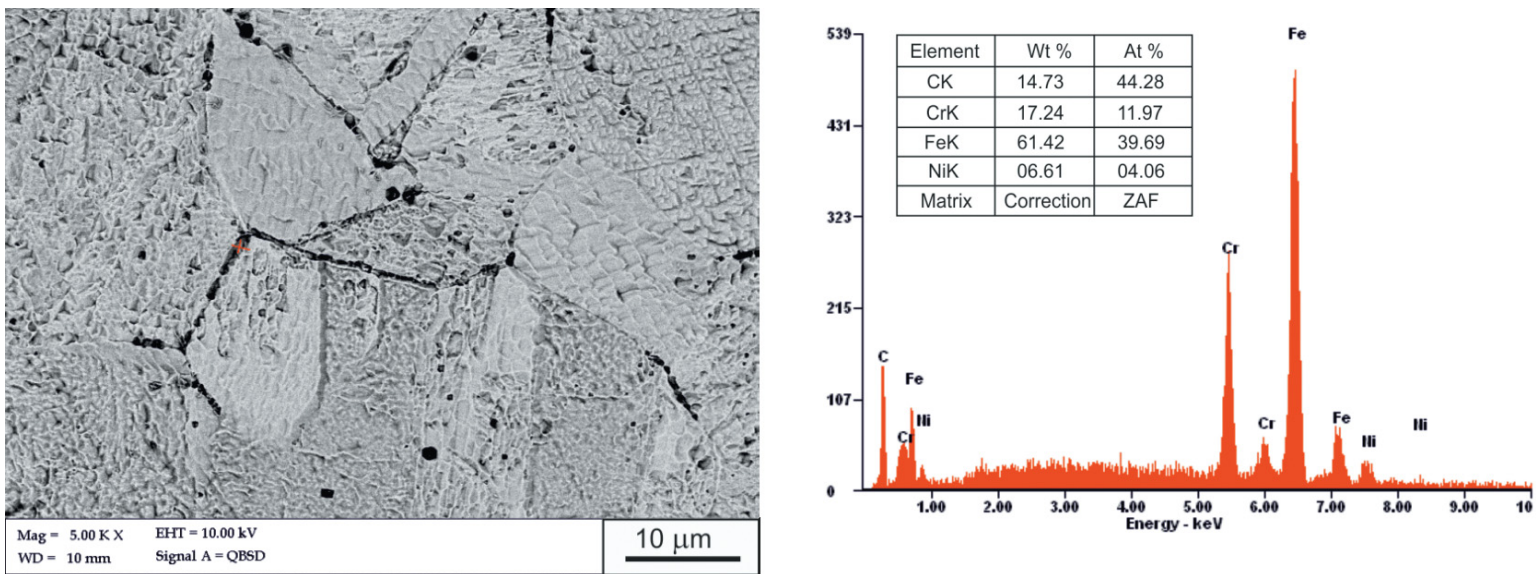

Fig. 5. $\mathrm{M}_{23} \mathrm{C}_{6}$ carbides precipitations along the grain boundaries (a), EDS analysis of the of $\mathrm{M}_{23} \mathrm{C}_{6}$ carbides (b)
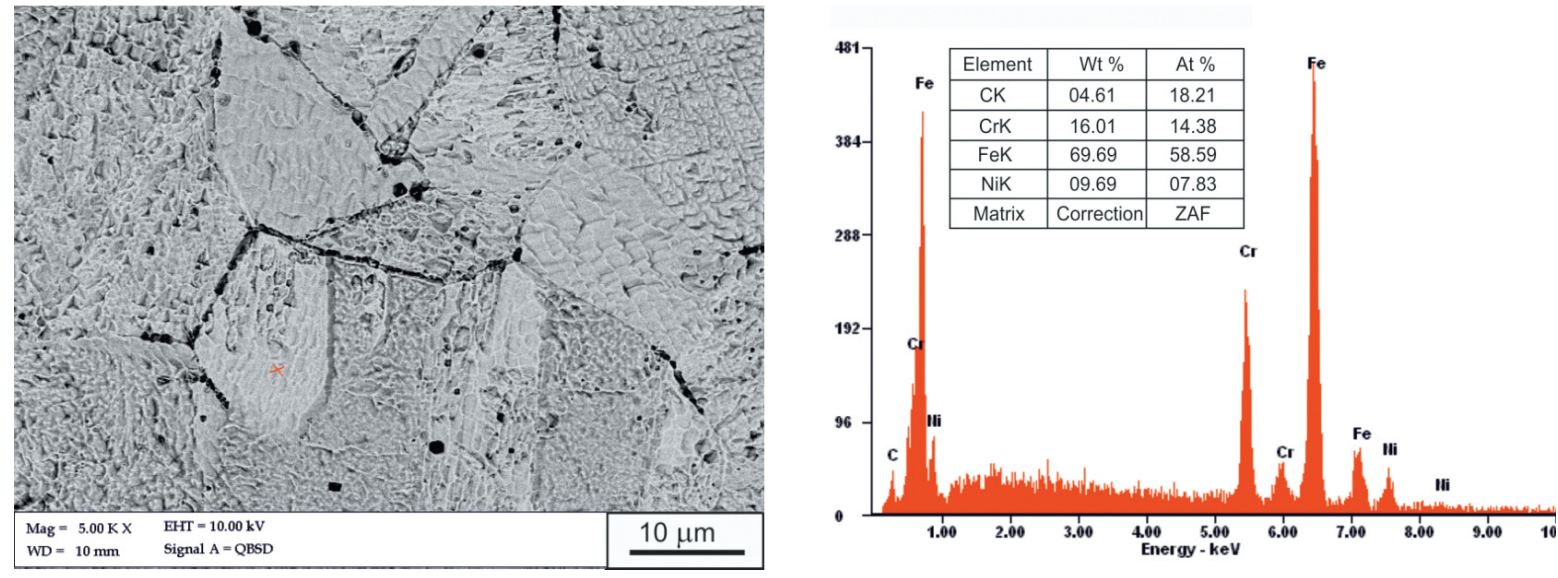

Fig. 6. Structure of X5CrNi18-10 steel after sensitization (a), EDS analysis of the matrix (b)

To determine the effect of the applied heat treatment on the mechanical properties the hardness measurements were performed using Vickers method. The results, which are average values of 10 measurements are shown in Fig. 7. Analyzed steel in delivery state had the highest hardness about 207 HV1 with

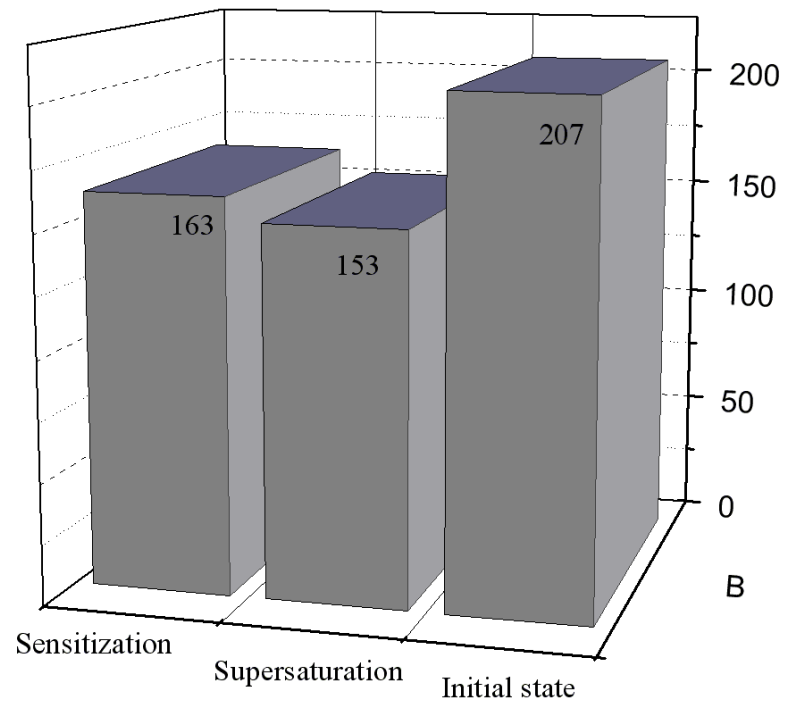

Fig. 7. The hardness of the investigated alloy in initial state and after heat treatment standard deviation $\mathrm{s}=2.95$. As a result of conducted supersaturation the decrease of the hardness value to $153 \mathrm{HV} 1(\mathrm{~s}=3.02)$ was stated. It is attributed to the austenite structure.

After the sensitization at $700^{\circ} \mathrm{C}$ the hardness increased to $163 \mathrm{HV} 1(\mathrm{~s}=1.51)$. The measured increase of hardness is the result of chromium carbides precipitation.

The results of potentiodynamic experiments conducted in artificial sea water $(3.5 \% \mathrm{NaCl})$ are shown in Table 3 and the course of changes of current density as a function of potential is presented in Fig. 8. It was found that the analyzed steel had varied resistance to the corrosion. Specimens after supersaturation are characterized by the highest corrosion resistance. The value of the corrosion current density was $1.2 \mathrm{mAcm}^{-2}$, the corrosion potential $-266 \mathrm{mV}$, and the polarization resistance $45.40 \mathrm{k} \Omega \mathrm{cm}^{2}$. This is caused by a single-phase structure of austenite. The sensitized samples showed the lowest corrosion resistance (the corrosion current density increased to $6.13 \mathrm{mAcm}^{-2}$ and polarization resistance decreased to $10.33 \mathrm{k} \Omega \mathrm{cm}^{2}$ ). The decrease of corrosion resistance is associated with the precipitation of chromium carbides in the grain boundaries. These zones become anode surfaces with lower corrosion resistance, and may be attacked in a corrosion environment. Good corrosion resistance was stated in samples in the delivery state (corrosion current density $2.86 \mathrm{mAcm}^{-2}$ and polarization resistance decreased to $17.48 \mathrm{k} \Omega \mathrm{cm}^{2}$ ). 
TABLE 3

Results of potentiodynamic tests for specimens in initial state and after heat treatment

\begin{tabular}{|c|c|c|c|}
\hline \hline Material & $\mathbf{I}_{\mathbf{c o r}}\left[\mathbf{m A} / \mathbf{c m}^{2}\right]$ & $\mathbf{E}_{\mathbf{c o r}}[\mathbf{m V}]$ & $\mathbf{R}_{\mathbf{p}}\left[\mathbf{k} \mathbf{\Omega} \mathbf{c m}^{\mathbf{2}}\right]$ \\
\hline Delivery state & 2.86 & -328 & 17.48 \\
\hline Supersaturation & 1.2 & -266 & 45.40 \\
\hline Sensitization & 6.13 & -311 & 10.33 \\
\hline
\end{tabular}

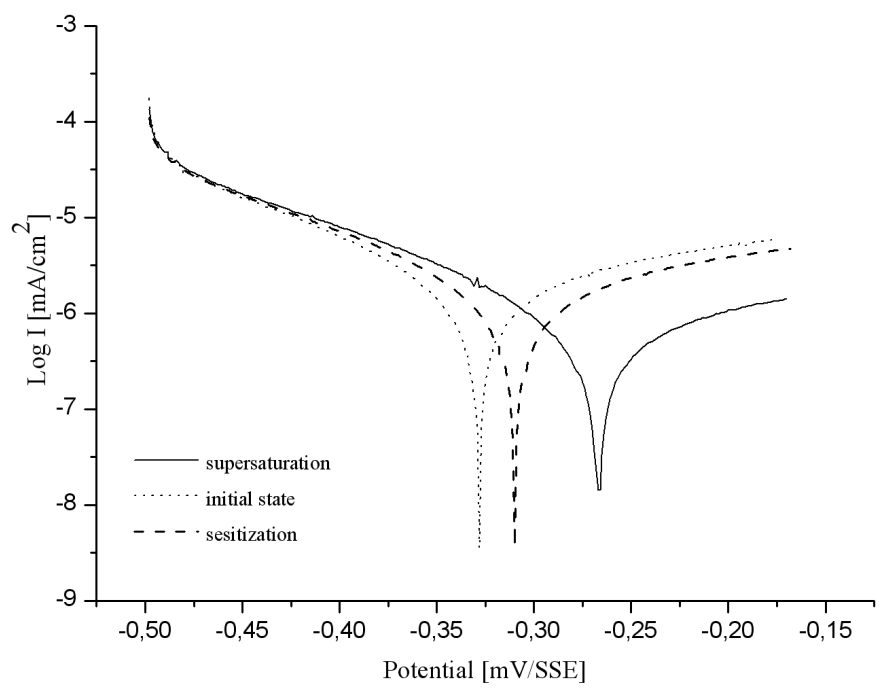

Fig. 8. Potentiodynamic polarization curves of the X5CrNi18-10 steel in initial state and after heat treatment obtained in artificial sea water
Observations of the sensitized samples after corrosion tests showed numerous and different corrosion damages. They revealed the presence of some cracks (Fig. 9a) and numerous pits of various shapes on the surface of the samples (Fig. 9b-d). The depth of pits is much greater than their diameter. Corrosion damage begins in places where the passivating oxide layer is breakdown. In the presence of aggressive small size chloride anions the ability of the material to correct its film is drastically limited. The surface of the pits become anode surrounded by large cathodic protective areas of the passive metal. The $\mathrm{pH}$ of the electrolyte inside the pits decreases which causes subsequent acceleration of the corrosion process. Local damage can lead to the destruction of the material through the perforation.

The morphology of corrosion damages after potentiodynamic tests was studied by SEM with EDS. The precipitation of chromium carbides was revealed inside some pits (Fig. 10a) with presence of such elements as shown in Fig. 10b. This confirms forming of zones depleted with chromium and carbon in the region adjacent to the carbides after sensitization.

\section{Conclusions}

The paper presents the influence of the heat treatment on corrosion resistance of austenitic stainless steel X5CrNi18-10. It has been concluded that sensitized material corroded signifi-
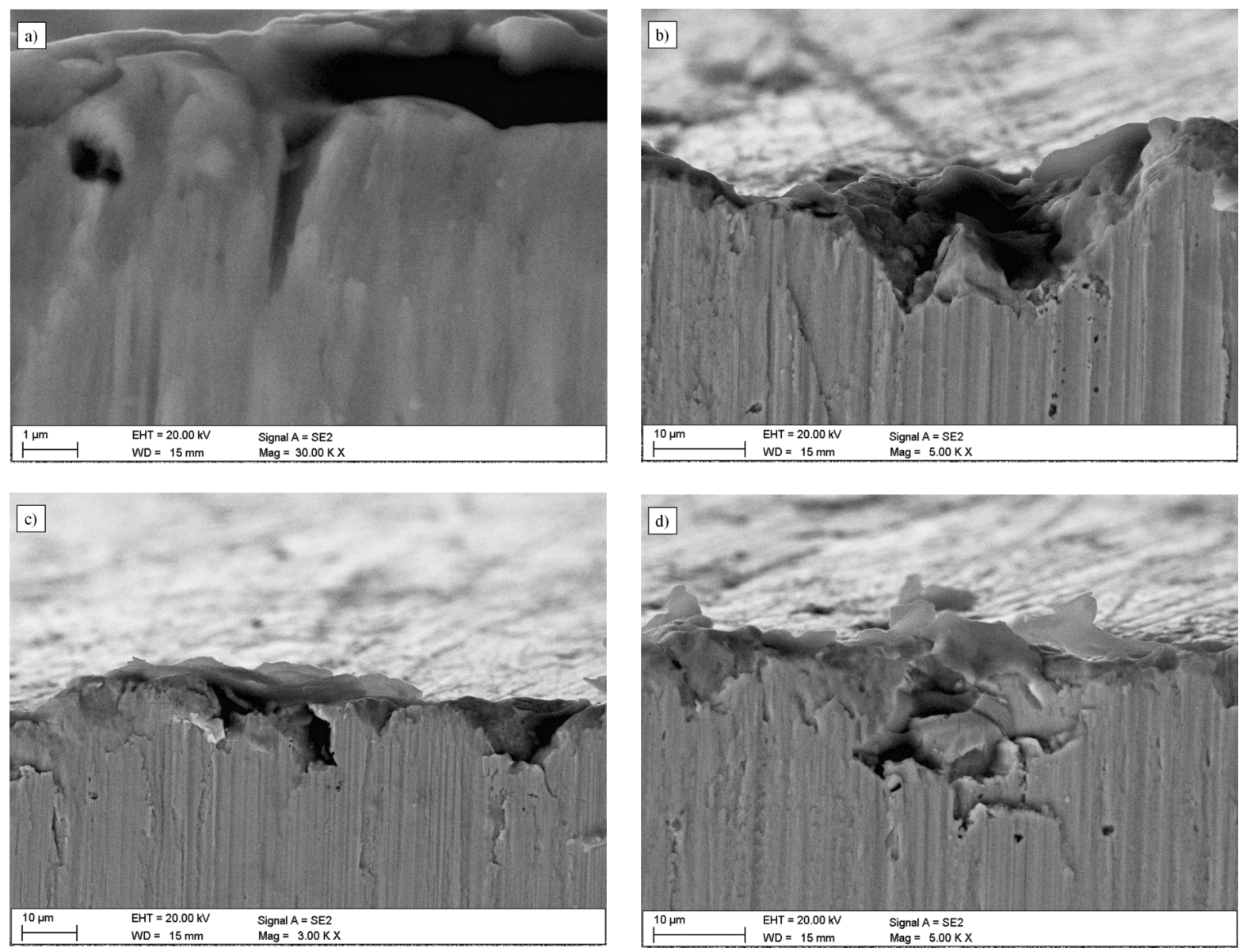

Fig. 9. SEM micrographs of X5CrNi18-10 steel after corrosion tests: cracs (a), pits with different shape and depth (b-d) 

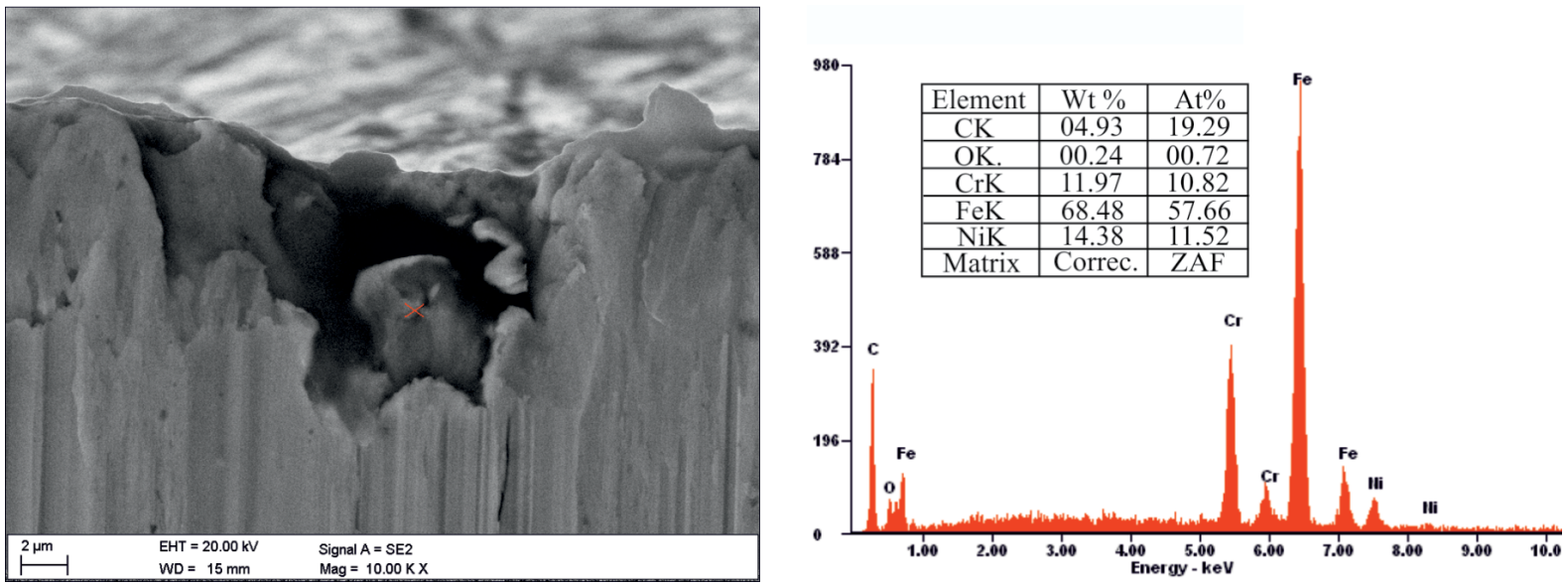

Fig. 10. SEM micrographs of the precipitated chromium carbide (a), EDS analyses from the particle inside the pit

cantly more than supersaturated samples or in delivery state. It was also stated that after sensitization decreased pitting resistance and the austenitic stainless steel was susceptible to intergranular corrosion which was a consequence of precipitated chromium carbides at grain boundaries. The electrochemical polarization curves exhibited good corrosion resistance after supersaturation but poor corrosion resistance of sensitized austenitic stainless steel in $\mathrm{NaCl}$ solution.

The conducted fractographic tests after corrosion allowed to determine the type and degree of destruction of the material. The presence of some cracks and numerous pits of diversified shape and size on the surface of the samples was revealed. The depth of pits was much greater than their diameter.

Austenitic stainless steel X5CrNi18-10 can be more satisfactory for the marine applications under certain conditions i.e. proper heat treatment - supersaturation above $1000^{\circ} \mathrm{C}$, lower concentration of carbon and stabilization by carbide forming elements like titanium or niobium.

\section{Acknowledgements}

This work was supported by the Ministry of Science and Higher Education of Poland as the statutory financial grant of the Faculty of Mechanical Engineering, Silesian University of Technology

\section{REFERENCES}

[1] M. Głowacka, Metaloznawstwo, 1996 Gdańsk.

[2] http://www.asminternational.org/documents/10192/3473958/ 05231G_Sample.pdf/7c5e4830-b443-4c71-a8c8-1a85c5b39dc5

[3] M. Shimada, H. Kokawa, Z.J. Wang, Y.S. Sato, I. Karibe, Acta Mater. 50, 2331-2341 (2002).

[4] A. Grajcar, M. Kciuk, S. Topolska, A. Płachcińska. J. Mater. Eng. Perform. 26 (6), 2245-2254.

[5] J. Marciniak, Biomateriały. Wydawnictwo Politechniki Śląskiej: 2002 Gliwice.

[6] Z. Brytan, Vademecum stali nierdzewnej, Stowarzyszenie Stal Nierdzewna: 2014 Katowice.

[7] R. Jones, V. Randle, Materials Science and Engineering A. 527, 4275-4280 (2010).

[8] C.T. Kwok, S.L. Fong, F.T. Cheng, H.C. Man. J. Mater. Process. Technol. 176, 168-178 (2006).

[9] R.T. Loto, J. Mater. Environ. Sci. 4 (4), 448-459 (2013).

[10] Y.F. Yin, R.G. Faulkner, Corrosion Science 49, 2177-2197 (2007).

[11] G. Han, J. He, S. Fukuyama, K. Yokogawa, Acta Mater. 46 (13), 4559-4570 (1998).

[12] J.B. Gnanamoorthy, Proc. Indian Acad. Sci. (Chem. Sci.) 97, 495-511 (1986).

[13] R. Singh, S.G. Chowdhury, B.R. Kumar, S.K. Das, P.K. De, I. Chattoraj, Scripta Mater. 57, 185-188 (2007).

[14] A. Almubarak, W. Abuhaimed, A. Almazrouee, International Journal of Electrochemistry (2013), DOI: 10.1155/2013/970835. 